\title{
GÊNERO E SEXUALIDADE NA EDUCAÇÃO BRASILEIRA CONTEMPORÂNEA
}

\author{
GENDER AND SEXUALITY IN CONTEMPORARY BRAZILIAN EDUCATION
}

\author{
Diogo dos Santos Martins ${ }^{1}$
}

RESUMO: $\mathrm{Na}$ contemporaneidade, o Brasil se encontra em uma posição preocupante no que diz respeito as transgressões de direitos, especialmente no que tange às minorias sexuais. Tendo em consideração que esta posição produz intenso padecimento, é importante estabelecer espaços para discussões, acesso à informações e reflexões que possam aumentar a densidade e perceptibilidade das questões sociais envolvendo gênero e sexualidade. E dar espaço a pessoas divergentes ao heteronormativíssimo que está presente na sociedade por meio dos processos consuetudinários, midiáticos, históricos, artísticos, políticos e institucionais do estado, formulando uma ideologia homofóbica de machos e fêmeas. Este artigo objetiva patentear as temáticas relacionadas ao gênero e à sexualidade, abordando história, condições e sociedade.

Palavras-chave: Gênero. Sexualidade. História. Condições. Sociedade.

ABSTRACT: Nowadays, Brazil is in a worrying position with regard to transgressions of rights, especially with regard to sexual minorities. Bearing in mind that this position produces intense suffering, it is important to establish spaces for discussions, access to information and reflections that can increase the density and perception of social issues involving gender and sexuality. And to give space to people who are different from the heteronormative that is present in society through the customary, media, historical, artistic, political and institutional processes of the state, formulating a homophobic ideology of males and females. This article aims to patent the themes related to gender and sexuality, addressing history, conditions and society.

Keywords: Gender. Sexuality, History, Conditions, Society.

\footnotetext{
I Acadêmico de Direito e de Ciência Política com ênfase em Relações internacionais. Possui extensão em; DIREITO PENAL E PROCESSO PENAL, Universidade Pitágoras/ Unopar. DIREITO IMOBILIÁRIO, Universidade Pitágoras Unopar. DIREITO MÉDICO E DA SAÚDE, Faculdade de Tecnologia de Curitiba. CONTRATOS, Instituto Federal de Educação, Ciência e Tecnologia do Rio Grande do Sul. DIREITOS HUMANOS E MIGRAÇÃO, Núcleo de apoio à migrantes e refugiados (NAMIR-UFBA), Universidade Federal da Bahia. E-mail: diogomartinssp@gmail.com
} 


\section{INTRODUÇÃO}

Hodiernamente, vivemos em uma conjuntura demasiadamente preocupante em termos de transgressões de direitos nas categorias de gênero e sexualidade. $\mathrm{Na}$ atualidade, o Brasil apresenta números tenebrosos em relação à realidade da classe LGBT+ (Lésbicas, Gays, Bissexuais, Travestis, Transexuais e mais), de acordo com a revisa Exame (2020), o país ocupa o inglório topo do ranking dos mais violentos para essa população pelo ${ }^{2} 2^{\circ}$ ano consecutivo. Só no ano de 2020 foram reportados mais de 350 assassinatos, que foram motivados por LGBTfóbia. O Brasil apresenta uma quantidade maior de assassinatos do que em países em que há previsão de pena de morte contra a população LGBT.

O Brasil se sistematiza de forma errônea para pautar as questões de gênero e sexualidade. As famílias possuem o direito à liberdade de educar seus filhos de acordo com suas ideologias (éticas, morais, religiosas e sociais). O estado tem o dever de apresentar elementos culturais na sua pluralidade e diversidade que não seriam explanados de forma esquematizada pelas famílias. Os territórios educativos, principalmente, as escolas e instituições de ensino superior, deveriam, se encarregar de apresentar novos horizontes, que não desqualifica os saberes familiares, mas que ampliam o espectro de questões presentes. No cotidiano, percebe-se que há uma resistência do estado brasileiro, democrático de direitos se manter laico. Já que há a coação dos grupos conservadores (em sua maioria religiosos), que buscam abolir as pautas de gênero e sexualidade da esfera estatal, negando veementemente as assustadoras informações precedentemente expostas.

\section{IDENTIDADE DE GÊNERO, SEXUALIDADE E SEXO}

É necessário que haja uma desagregação da concepção subjetiva que associa Identidade de gênero, sexualidade e sexo, para quebrar os estigmas presentes na sociedade brasileira. Logo, faz-se necessário adentrarmos no significado destas palavras. Segundo o psicólogo Marcos Santos: 
A sexualidade envolve tudo o que nos constitui humanos, enquanto o sexo é uma parte integrante de nossa biologia. Já a identidade de gênero é a parte psicológica íntima da pessoa, que pode ou não se conformar ao seu meio externo. (SANTOS MARCOS, 2020).

De uma forma mais cognoscível, o sexo diz respeito às características físicas de um indivíduo proveniente de uma combinação cromossômica, está relacionada com a existência de órgãos genitais, ou seja, o pênis, a vagina, ambos ou nenhum deles, e com a caracterização de macho, fêmea ou intersexo. A sexualidade é conceituada como à atração que se sente por outros indivíduos, assim, se a pessoa sente atração afetiva e sexual por pessoas do sexo ou gênero oposto, ela é denominada heterossexual ou heteroafetiva. Se à atração afetiva e sexual é por aqueles do mesmo sexo ou gênero, sua orientação é homossexual ou homoafetiva, se à atração afetiva e sexual for pelos dois sexos ou gêneros, homem e mulher, a pessoa é denominada de bissexual ou biafetiva, há também aqueles que não sentem atração afetiva e sexual por nenhum sexo ou gênero, que são os assexuais, segundo o psicólogo Paulo Alencar (2018), a assexualidade ainda pode ser uma "sexualidade" em construção.

A formação da identidade de gênero diz respeito a como a pessoa se identifica culturalmente, psicologicamente e socialmente, há também as características comportamentais, que são atribuídas pela sociedade sob as expectativas do ser Homem ou do ser Mulher, conforme alegou Scott (1994).

Estamos inseridos em um corpo social que se baseia em costumes, ou seja, decrépito e formulado à base de padrões e praxes que impele o indivíduo a seguir arquétipos preliminarmente estipulados que correlacionam sexo, gênero e sexualidade, alienando-lhe no direito de construção da sua personalidade. (Foucault, 1999).

Refere-se a um padrão cultural naturalizado no processo de reprodução que préestabelece a identidade de gênero e à sexualidade. A contar da gravidez, a forma de tratamento e os trajes das crianças são idealizados e baseados em expectações sociais e culturais de gêneros binários, que dependem da descoberta do sexo biológico do bebê.

Ábdito de estigmas, Goffman (1988) nos ajuda a refletir que, a identidade de gênero de um heterossexual pode ser tanto masculina como feminina quanto não 
binária, assim como também a de um homossexual, bissexual, intersexual, transexual, assexual ou pansexual. Scott (1994) reforçando esta linha de raciocínio, afirma que gênero além de ser um conceito subjetivo e fluido é também uma construção cultural da sociedade. Ainda nesta linha de raciocínio afirma Auad (2004):

Gênero não é sinônimo de sexo (macho ou fêmea), mas corresponde ao conjunto de representações que cada sociedade constrói, através de sua História, para atribuir significados, símbolos e características para cada um dos sexos. Assim, as diferenças biológicas entre homens e mulheres são interpretadas segundo as construções de gênero de cada sociedade (Auad, 2004, p. 28).

Gênero concerne a conduta sociais diferentes, se trata de uma estruturação social criada para atribuir ao indivíduo nascido com um pênis ou uma vagina as condições de ser homem ou mulher. Quando o indivíduo não exerce um papel de gênero conforme a expectativa da sociedade, ele acaba por sofrer diversas transgressões, sejam elas físicas, psicológicas, morais.

Os estigmas presentes no corpo social quanto à pluralidade humana é um fato social de excessivo destaque e resulta-se em discriminação e segregação que embasa uma variedade de infortúnios. Segundo Norberto Bobbio (2002) na obra Elogio da Serenidade, o preconceito institui-se de posições desacertadas, que são aceitas passivamente, sem averiguação do crivo do raciocínio e comprovações cientificas, denotando fundamentos conservadores que se opõe a equidade.

No artigo, Edmund Burke e a gênese conservadorismo, citado por Souza (2016), pode-se compreender que visando um padrão uniforme das hegemonias, o conservadorismo atua sobre as situações pessoais e sociais no cotidiano das pessoas, orientando o que deve ou não ser definido como "normal” ou "patológico" a partir das ideias durkheimianas de “organismo social”. Essas circunstâncias acontecem frequentemente livéis impercebíveis, em virtude dos estigmas nos indivíduos e no corpo social conservador. Constantemente um indivíduo reproduz um pré-julgamento sem se dar conta do seu preconceito, ou seja, por não ter a capacidade de alteridade ou 
conhecimento real da questão reproduz normalmente o que suas limitações educacionais ou empíricas determinam.

Embora o preconceito seja natural no ser humano, a discriminação não é. A discriminação, segundo Dayane Borges (2020), na maior parte das vezes é a aversão ao que é diferente, de acordo com o que a sociedade julga como normal, uma atitude discriminatória resulta na destruição ou comprometimento dos direitos fundamentais do ser humano, prejudicando um indivíduo no seu contexto social, cultural, político ou econômico.

$\mathrm{Na}$ contemporaneidade ainda há retrocessos em relação aos Direitos Humanos dos indivíduos que se distinguem do padrão heterossexual. As transgressões referentes à diversidade sexual e identidade de gênero são conjunturas midiáticas e afetam toda a sociedade. Apesar de ser um desfecho, o homicídio é apenas uma das violências dentre as muitas que são consideradas menores, como as discriminações e agressões físicas, morais, verbais e psicológicas. (Mott, Michels \& Paulinho, 2018).

Atualmente, o sexismo pode não comprometer o escrutínio, mas ainda controla a família, os papéis sociais, e a especificidade humana, porque fomenta uma singular de heteronormatividade que, de maneira natural, impõe um conservadorismo sobre as condições plurais da natureza humana formulando uma hegemonia social causadora de sofrimento moral as pessoas que divergem.

Sob todos estes aspetos expostos, corrobora que muitos impasses e angústias são provocados por esta organização que estabelece as condições de gênero e sexualidade e baliza todo o corpo social e complexifica as relações humanas, determinando, compelindo, oprimindo, coagindo, segregando e violentando o direito natural e pessoal de cada pessoa gozar a multiplicidade da sua sexualidade e identidade de gênero.

\section{POPULAÇÃO LGBT+ E O ACESSO Á EDUCAÇÃO}

Com o intuito de que o corpo social seja construído de forma diversificada, plural, igualitária e democrática é preciso admitir a educação como um direito fundamental e 
indispensável a todos sem diferenciação de gênero ou sexualidade. As escolas e instituições de ensino possuem um importante papel na formação ética e moral dos seres e no combate as transgressões destas minorias formando um raciocínio crítico e pautado nos direitos humanos.

Atualmente, estamos inseridos em um corpo social marcado historicamente pelo atentado e negação dos direitos, como também pela proliferação do irrespeito à diversidade e multiplicidade. A discriminação é apenas uma das múltiplas violências que se exteriorizam nos ambientes escolares e educacionais, isso reflete na preservação do acesso e em especial na permanência das minorias, bem como a população LGBT+, que por não se encaixam aos arquétipos que são impostos rudemente pela heteronormatividade contemporânea, são amiudadamente expostos a um ambiente de segregação, marginalização, são foco dos discursos de ódio e da violência física e psicológica. De acordo com Junqueira (2009):

\footnotetext{
A escola configura-se um lugar de opressão, discriminação e preconceitos, no qual e em torno do qual existe um preocupante quadro de violência a que estão submetidos milhões de jovens e adultos LGBT - muitos/as dos/as quais vivem, de maneiras distintas, situações delicadas e vulneradoras de internalização da homofobia, negação, auto culpabilização, auto aversão. E isso se faz com a participação ou a omissão da família, da comunidade escolar, da sociedade e do Estado. (JUNQUEIRA, 2009).
}

Legitimando a colocação feita por Junqueira (2009), Maia (2009) menciona que em inúmeras vezes a comunidade escolar prefere se abster "diante do preconceito e da violência inerente a tais padrões, o que reforça a discriminação e impede a inclusão social de todos" (MAIA, 2009, p. 286-287). As escolas brasileiras foram historicamente formadas de acordo com os padrões, concepções, e ideologias conservadoras e heteronormativas, alicerçadas a única referência identitária: a do homem branco, heterossexual e de classe média, perdurando até a contemporaneidade como uma forma de caracterização do normal, objetivando subordinar as práticas sociais, sexuais e de gênero da população.

Portanto, cabe à escola debater pautas que afetam à dignidade da pessoa humana, tais como a violação de direitos fundamentais, a discriminação sexual e de gênero. Além de 
que se compatibiliza às escolas apresentar novos horizontes, que não desqualifica os saberes familiares, mas que ampliam o espectro de questões presentes e ensinar mais do que, apenas, conteúdos programáticos, sendo necessário a preparação de cidadãos aptos a mudar essa disparatada realidade e a respeitar a diversidade e a pluralidade. Somente assim, as escolas contribuíram de forma eficiente no combate às transgressões de direitos no seu meio e no corpo social, favorecendo a construção de uma consciência crítica e de práticas de respeito a diversidade e a pluralidade, contribuindo para uma sociedade mais acolhedora e menos excludente.

\section{CONCLUSÃO}

Diante de tudo que foi exposto, urge necessário que os professores/as reexaminem o formato de executar à sua maneira de cooperação profissional da educação para a edificação de um corpo social mais justo, igualitário e democrático, sendo assim, menos excludente.

Com referência ao estado é cristalina a necessidade de admissão de mais políticas públicas pautadas na educação e no acesso à informação, como umas das formas de garantir o direito de todo o corpo social.

\section{REFERÊNCIAS BIBLIOGRÁFICAS}

AUAD, Daniela. Educar meninas e meninos: relações de gênero na escola. São Paulo: Contexto, 2006. . Acessado em: 28 de março. 2021.

DISCRIMINAÇÃO, o que é? Definição, principais tipos e como acontece. [S. l.]: Dayane Borges, 2020. Disponível em: https://conhecimentocientifico.r7.com/discriminacao/. Acesso em: II mar. 202I.

ENTENDA a diferença entre sexo biológico, identidade de gênero, expressão de gênero e orientação sexual. [S. 1.]: PAULO ALENCAR, I9 mar. 2018. Disponível em: https://psicologopauloalencar.com.br/entenda-a-diferenca-entre-sexo-biologicoidentidade-de-genero-expressao-de-genero-e-orientacao-sexual/. Acesso em: I8 fev. 202I. 
ET 35: SEXUALIDADES E GÊNERO NA ESCOLA: O QUE PENSAM E COMO ATUAM OS PROFESSORES EM RELAÇÃO A ESSA TEMÁTICA?: O QUE DIZEM OS MARCOS LEGAIS PARA ABORDAGEM DE GÊNERO E SEXUALIDADES NA ESCOLA?. [S. 1.]: Angela Maria Venturini, André Luiz dos Santos Barbosa, Rita de Cássia de Souza da Silva, I9 mar. 2018. Disponível em: https://www.editorarealize.com.br/editora/anais/enlacando/2017/TRABALHO_EVo72_ MDi_SA35_ID702_19062017165436.pdf. Acesso em: 21 fev. 2021.

FENÓTIPO. [S. 1.]: Isabela Canhas, I9 mar. 2018. Disponível em: https://www.infoescola.com/genetica/fenotipo/. Acesso em: 2I fev. 202I.

GOFFMAN, Erving. Estigma: Notas sobre a Manipulação da Identidade Deteriorada, Rio de Janeiro, Editora LTC, I988. . Acessado em: 22 de março. 2021.

IDENTIDADE de gênero, sexualidade e sexo: entenda os termos: Sexualidade engloba conceitos como orientação sexual, enquanto a identidade de gênero é como a pessoa se percebe no mundo. In: Identidade de gênero, sexualidade e sexo: entenda os termos: Sexualidade engloba conceitos como orientação sexual, enquanto a identidade de gênero é como a pessoa se percebe no mundo. [S. 1.]: Redação Minha Vida, ıo ago. 2020. Disponível

em: https://www.minhavida.com.br/bem-estar/materias/36624-identidade-de-generosexualidade-e-sexo-entenda-os-termos. Acesso em: I4 jan. 2021.

JUNQUEIRA, R. Diversidade sexual na Educação: problematizações sobre a homofobia nas escolas (Org.). Brasília: MEC/Secad/Unesco, 2009. Acessado em: 22 de março. 2021.

MAS AFINAL, qual o significado de $\mathrm{LGBTQQICAPF}_{2} \mathrm{~K}+$ e outras siglas como LGBTQ+?: Rejeição familiar, marginalização econômica e impunidade explicam a alta contínua dos números; inclusão no mercado de trabalho poderia reverter cenário. [S. 1.]: JÉSSICA SOUZA, 27 ago. 2019. Disponível em: https://razoesparaacreditar.com/significado-lgbtqqicapf 2k/. Acesso em: 2 fev. 202I. MICHEL FOUCAULT. VIGIAR E PUNIR. NASCIMENTO DA PRISÃO. Tradução de. Raquel Ramalhete. 20 a. Edição. Petrópolis. 1999.. Acessado em: 22 de março. 202I. MOTT, Luiz. MICHELS, Eduardo, PAULINHO. Mortes violentas de LGBT no Brasil: Relatório 2017 . Disponível em: 
https://homofobiamata.files.wordpress.com/2017/12/relatorio-2081.pdf. Acesso em: I9 jan. 2021.

MOTT, Luiz. MICHELS, Eduardo, PAULINHO. Mortes violentas de LGBT+ no Brasil: relatório 2018.

Disponível em: https://homofobiamata.files.wordpress.com/2019/oI/relatorio-2018-I.pdf. Acesso em: 2I fev. 2021.

PELO ${ }_{12}{ }^{-}$ano consecutivo, Brasil é país que mais mata transexuais no mundo: Rejeição familiar, marginalização econômica e impunidade explicam a alta contínua dos números; inclusão no mercado de trabalho poderia reverter cenário. [S. 1.]: Gabriel Justo, i9 nov. 2020. Disponível em: https://exame.com/brasil/pelo-I2o-ano-consecutivo-brasil-e-paisque-mais-mata-transexuais-no-mundo/. Acesso em: 2 fev. 2021.

QUAL a diferença entre sexo e gênero (e por que esses termos podem estar ficando obsoletos). [S. 1.]: Beatriz Díez, II set. 2020. Disponível em: https://www.bbc.com/portuguese/curiosidades-54123807. Acesso em: 26 fev. 2021.

SCOTT, J. Gender and the Politics of History. New York: Columbia University Press, 1988. Acessado em: 22 de março. 2021.

SEXO biológico, identidade de gênero e orientação sexual. [S. 1.]: MVC EDITORA, 2020. Disponível em: https://mvceditora.com.br/2020/o5/18/sexo-biologico-identidade-degenero-e-orientacao-sexual/. Acesso em: 28 fev. 202I.

SEXO e Sexualidade são a mesma coisa? Todo mundo tem sexualidade?: Quando começa a sexualidades? Eu posso viver a minha sexualidade livre de preconceitos, medos e falsas crenças?. [S. l.]: Vivendo a Adolescência, 2021. Disponível em: http://www.adolescencia.org.br/site-pt-br/sexualidade. Acesso em: 8 mar. 202I. SEXUALIDADE, gênero e sexo biológico. [S. 1.]: MANUAL DA COMUNICAÇÃO LGBTQIA+, 2021. Disponível em: https://grupodignidade.org.br/consultapublica/2sexualidade-genero-e-sexo-biologico/. Acesso em: 6 mar. 202I.

SEXUALIDADE, Identidade e Orientação. Você sabe a diferença?. [S. l.]: Thales Nobre Quaresma Araujo, 2020. Disponível em: https://www.vittude.com/blog/falapsico/sexualidade/. Acesso em: 9 mar. 2021. 
SIGNIFICADO de Discriminação. [S. l.]: Portal galedes, 2015. Disponível em: https://www.geledes.org.br/significado-de-discriminacao/. Acesso em: 13 mar. 202I.

Superior Tribunal de Justiça. Agravo Regimental no Recurso Especial n.I.055.886-PB. Relator: Ministro. Napoleão Nunes Maia Filho, I out. 2009. 